\title{
O Grupo Operativo Intervindo na Síndrome de Burnout
}

\author{
Intervenção em Burnout
}

\author{
Vivien Rose Böck \\ Jorge Castellá Sarriera
}

\begin{abstract}
Resumo
O presente estudo teve como objetivo verificar a alteração do nível de Burnout em professores por intermédio da intervenção da técnica de grupos operativos. A amostra foi composta por professores de $5^{\mathrm{a}}$ a $8^{\mathrm{a}}$ série de uma escola particular de Porto Alegre, subdividindo-se em dois grupos, o de controle e o experimental, com 12 professores em cada grupo. Para medir a Síndrome de Burnout foi utilizado o MBI (Maslach Burnout Inventory). Após a primeira aplicação do teste em todos os professores, realizaram-se 9 encontros sob a técnica de grupos operativos com o grupo experimental e posteriormente, todos responderam novamente ao teste. Os resultados demonstraram aumento do nível de Burnout, bem como nas suas dimensões: esgotamento emocional, realização profissional e despersonalização para o grupo experimental. Na análise da intervenção constatou-se a importância tanto da sensibilização profissional do trabalho docente como do apoio social entre os professores como estratégias para a prevenção e o enfrentamento da Síndrome de Burnout. Palavras-chaves: Burnout; Grupo psicoterápico; Estresse.
\end{abstract}

\section{Operative group as intervention resource in the Burnout Syndrome}

\begin{abstract}
The objective of this study is to check the changes in Burnout levels in teachers through the operative group technic. The investigation of the research follows a mix of qualitative and quantitative methods. The sample was composed by teachers from fifth to eighth grade in a private school of Porto Alegre. They were divided in two groups, the control one and the experimental one with 12 teachers. The MBI (Maslach Burnout Inventory) was used to measure the Burnout Syndrome. After the application of first test in all teachers, 9 meetings were held using the operative group technic with the experimental group and later on, all answered the test again. In the quantitative analysis the results confirmed the hypothesis of having a change in the Burnout level, as well as their dimensions: emotional exhaustion, professional accomplishment and depersonalization. In the qualitative part of the study, through the subject analysis and the group process, it was concluded that the professional awareness and the social support among teachers as strategies to prevent and face the Bornout Syndrome are important.
\end{abstract}

Keyword: Burnout; Group Psychotherapy; Stress.

\section{El grupo operativo interviniendo en el síndrome de Burnout}

\section{Resumen}

Este estudio ha tenido como objetivo verificar la alteración del nivel de Burnout en profesores por medio de una intervención de la técnica de grupos operativos. La muestra ha sido compuesta por profesores de $5^{\circ}$ a $8^{\circ}$ grado de una escuela privada de Porto Alegre, divididos en dos grupos, uno control y otro experimental, con 12 profesores en cada grupo. Para medir el síndrome de Burnout ha sido utilizado el MBI (Maslach Burnout Inventory). Después de la primera aplicación del test en todos los profesores, se han realizado 9 reuniones con la técnica de grupos operativos en el grupo experimental, y después todos respondieron nuevamente el test. Los resultados han demostrado un aumento del nivel de Burnout así como en sus dimensiones: agotamiento emocional, realización profesional y despersonalización para el grupo experimental. En el análisis de la intervención se ha constatado la importancia de la sensibilidad profesional de trabajo docente así como del apoyo social entre los profesores como estrategias para prevenir y enfrentar el síndrome de Burnout. Palabras clave: Burnout, Grupo Psicoterapéutico; Stress. 


\section{Introdução}

A educação é um processo eminentemente relacional. Professor e aluno podem ser transformados, um pelo outro, através de uma relação direta, permeada por afeto e por trocas de informações, conhecimentos e comportamentos. A relação pedagógica, enquanto relação humana, ultrapassa os limites profissionais e escolares dos anos letivos. É uma relação que deixa marcas na vida (Lobo, 1999). Apesar de um influenciar o outro dinamicamente, é o professor que exerce maior influência no processo de formação e de desenvolvimento dos alunos (Witter, 2003).

Por meio de estudos realizados (Carlotto, 2002; Codo, 2000; Moura, 1997; Esteves, 1994), constatase grande número de docentes irritados, desmotivados, cansados, sem encontrar significado pessoal no seu trabalho e sentindo-se desvalorizados profissionalmente. Essa condição de desistência emocional no trabalho é considerada como um malestar docente encontrado em toda sociedade ocidental (Jesus, 1998).

No Brasil, já existe legislação neste sentido, a Lei $n^{\circ}$ 3.048/99 (Lei que regulamenta a Previdência Social), que contempla a Síndrome de Esgotamento Profissional (Burnout) como doença do trabalho. A situação nos Estados Unidos é tão grave, que a profissão é considerada como de alto risco, pelas companhias de seguro americanas.

As pesquisas realizadas em relação a Burnout centram-se principalmente nas variáveis demográficas e de personalidade (Carlotto, 2002; Codo, 2000; Moura, 1997). Ao analisar a produção arrolada na base bibliográfica PsycArticle, de 1987 a 2002, Witter (2003) constatou que somente 28 artigos apresentaram estudos sobre a relação professorestresse, concluindo haver necessidade de pesquisas sobre a área principalmente no sentido de propor programas de intervenção e prevenção. Maslach e Leiter (1999) alertam sobre os custos gerados pela indiferença com que as organizações lidam com o problema e defendem que a melhor forma de prevenção e de tratamento é enfocá-lo de modo coletivo e organizacional e não apenas individual.
Este estudo compartilha desta perspectiva de intervenção para a mudança e entende a Síndrome de Burnout, conforme Maslach e Leiter (1999), como um processo que se desenvolve na interação de características do ambiente de trabalho e características pessoais.

\section{A Síndrome de Burnout}

Maslach e Jackson (198I) definem a Síndrome de Burnout como uma reação à tensão crônica gerada principalmente nas pessoas que mantêm, em decorrência de sua profissão, contato direto e contínuo com outros seres humanos, profissionais que trabalham com qualquer tipo de cuidado interpessoal tais como: professores e enfermeiros. A Síndrome de Burnout é entendida, pelos autores citados, como um conceito multidimensional envolvendo três componentes;

Exaustão Emocional: sensação de esgotamento, de falta de energia e de recursos emocionais próprios para resolver os problemas diários. Este é o aspecto individual da síndrome;

Despersonalização: é o resultado da ocorrência de sentimentos e atitudes negativas para com a pessoa de que cuida (alunos, pacientes, clientes), dirigindose a elas com indiferença, frieza, ironia e cinismo, ou seja, uma "coisificação" da relação, sendo este o fator interpessoal de burnout.

Reduzida Realização Profissional: sentimentos de insatisfação profissional, de fracasso laboral, baixa autoestima, desmotivação e diminuição da eficiência no trabalho (Abreu, Stoll, Ramos, Baumgardt \& Kristensen, 2002).

Burnout surge quando o docente sente que seus recursos próprios são perdidos ou inadequados frente às exigências de seu trabalho e que trazem um retorno insatisfatório para suas próprias demandas de autoestima e reconhecimento profissional e social (Codo \& Vasques-Menezes, 2000). Esta situação é agravada quando os suportes social e afetivo do professor apresentam-se enfraquecidos ou mesmo ausentes. Buscando a resolução de problemas comuns e o fortalecimento de apoio mútuo, Jesus (200I) valoriza o trabalho de equipe, entre os docentes, como sendo o meio mais importante para a prevenção e superação do esgotamento profissional. 


\section{Grupo Operativo}

A técnica de grupo operativo, segundo PichonRivière (1977), é escolhida em função desta contemplar os principais quesitos para a remissão de Burnout dentro do âmbito escolar, pois favorece a partilha de experiências profissionais, a redução do isolamento, a retroalimentação emocional através de apoio social bem como o fornecimento de feedback, proporcionando o desenvolvimento pessoal e profissional dos professores. Esta abordagem grupal tem suas origens na teoria psicanalítica, principalmente nos aportes kleinianos (Osório, 2000). Segundo definição de seu criador, Enrique J. Pichon-Rivière (1977), o grupo operativo consiste de um grupo de pessoas centrados numa tarefa. $O$ fundamental na tarefa grupal consiste em superar e resolver situações fixas e estereotipadas, flexibilizando e permitindo questionamentos sobre o que era considerado imutável. A resistência à mudança suscita dois medos básicos: o medo da perda das estruturas existentes e conhecidas, apesar de estereotipadas, que ocasiona a ansiedade depressiva e o medo do ataque da nova situação que, por ser desconhecida e suscitar insegurança pelo receio de faltar recursos para enfrentá-la, cria a ansiedade paranóide.

A partir dos ECROS (esquema conceitual, referencial e operacional) individuais, o grupo constrói um esquema referencial grupal, obtendo um sentido de unidade e coerência entre seus membros. Os papéis desempenhados por cada membro no grupo são entendidos através da articulação de dois níveis: a verticalidade, relacionada à história pessoal da pessoa e a horizontalidade, que é a relação que acontece entre os integrantes. A interação grupal começa pela afiliação, onde a pessoa não se incorpora totalmente ao grupo e transforma-se em pertença, quando ocorre um sentimento de efetiva integração grupal. (Osório 2000).

O processo grupal principia com a fase de prétarefa, na qual o grupo divaga tendo dificuldade de centrar-se na tarefa. Evolui para a fase da tarefa, quando há a elaboração das ansiedades depressivas e persecutórias e na ruptura das estruturas estereotipadas. Finaliza com a fase do projeto em que os participantes constróem uma estratégia operativa, planificando para o futuro e enfrentam a situação de perda que advém do término da tarefa com a separação do grupo.

Assim, através do processo do grupo operativo com professores, os mecanismos de saúde podem ser construídos com o novo conhecimento decorrente de um conjunto de experiências e afetos que são mobilizados pelos próprios docentes, ao pensarem e agirem sobre as questões da vida docente. A proposta deste trabalho consiste em concretizar e sistematizar, através de intervenção de grupo operativo, um suporte social e afetivo para os professores, considerando a proposta inicial de remissão de Burnout.

\section{Método}

\section{Desenho da Pesquisa}

O desenho utilizado na presente pesquisa foi quase-experimental com um grupo experimental e um de controle, avaliados antes e depois da intervenção. A intervenção em grupo, utilizada em forma de grupo operativo baseado na definição de Pichon-Rivière (1977), configurou a variável independente. A variável dependente consistiu na avaliação da Síndrome de Burnout, pré e pós-teste, incluindo seus três componentes: Exaustão Emocional, Despersonalização e Reduzida Realização Profissional.

\section{Participantes}

Participaram da pesquisa 24 professores do Ensino Fundamental de $5^{\mathrm{a}}$ a $8^{\mathrm{a}}$ séries de uma escola particular de Porto Alegre, com nível superior completo. A amostra foi composta pelo grupo de professores selecionado aleatoriamente, através de sorteio, em dois grupos de 12 participantes cada: o grupo experimental e o de controle. Não houve critérios de inclusão/exclusão de participantes. Durante os grupos operativos 4 professores faltaram em encontros alternados, mas não houve desistências em relação à realização da pesquisa. 


\section{Instrumento}

Para avaliar a Síndrome de Burnout experienciada pelos professores foi utilizado o $\mathrm{MBI}$ - Maslach Burnout Inventory (Maslach \& Jackson, 198I), o qual fornece escores em três sub-escalas - Exaustão Emocional (9 itens), Despersonalização (5 itens) e Reduzida Realização Profissional (8 itens) - e um índice geral combinando as sub-escalas. $O$ instrumento é constituído por 22 itens, configurado em uma escala Likert de 5 pontos, iniciando com "I" como "nunca" a "5" como "todos os dias". Assim, entende-se que os escores médios em "I" representam baixo nível de Burnout; os escores médios em "2", nível médiobaixo; os escores médios em " 3 ", nível médio; os em "4" representam nível médio-alto e os de número "5" são consideradas nível alto de Burnout. Uma pessoa que apresente altas pontuações em Exaustão Emocional e Despersonalização, associadas a baixos valores em Realização profissional é considerada em Burnout (Benevides-Pereira, 2002). As propriedades psicométricas do $\mathrm{MBI}$ foram comprovadas em vários estudos. A consistência interna das três dimensões do inventário é satisfatória, apresentando um alfa de Cronbach que vai de 0,7l a 0,90 (Carlotto, 2002). Benevides-Pereira (2002) refere que o $\mathrm{MBI}$ possui validação fatorial (itens com saturação acima de 0,40 ), consistência interna (EE $=$ a de 0,90; $D E=a$ de 0,79 e $R P=$ a de $0,7 \mathrm{I})$, e validação convergente.

\section{Procedimento de Coleta e Análise de Dados}

O grupo experimental vivenciou 9 encontros sob a técnica de grupo operativo, tendo como tarefa debater a vida de professor. As reuniões foram realizadas no transcorrer de um semestre. Os encontros foram realizados nas dependências da própria escola, com intervalos médios de duas semanas entre eles, com a duração de uma hora cada. Esta sistemática correspondeu às diretrizes colocadas por Bleger (1985) que sugere que o grupo operativo deve funcionar com um tempo limitado e previsto e com uma freqüência regular. A tarefa proposta para os operativos foi o debate de como percebiam a profissão de professor. Como recursos, foram utilizados TV, videocassete, cartazes e revistas. Os encontros foram gravados integralmente em fita cassete. $O$ grupo de controle manteve suas atividades escolares normais. $O$ tratamento estatístico foi realizado através do contraste de médias, antes e depois da intervenção, utilizando o teste $t$ de student.

Por outro lado, houve interesse em analisar o processo vivenciado pelos docentes no decorrer das sessões do grupo operativo, centrado na discussão dos fatores de estresse e de realização no trabalho do professor, para avaliar qualitativamente o grau de impacto desta intervenção e possuir outro parâmetro de análise que pudesse fornecer elementos explicativos aos resultados estatísticos.

\section{Resultados}

Iniciou-se pela exposição dos resultados comparativos das médias relacionadas entre antes e depois da intervenção do grupo de controle e experimental, em relação ao nível de Burnout dos docentes. Conforme evidenciam a Figura I e a Tabela $\mathrm{I}$, antes da intervenção os grupos de controle e

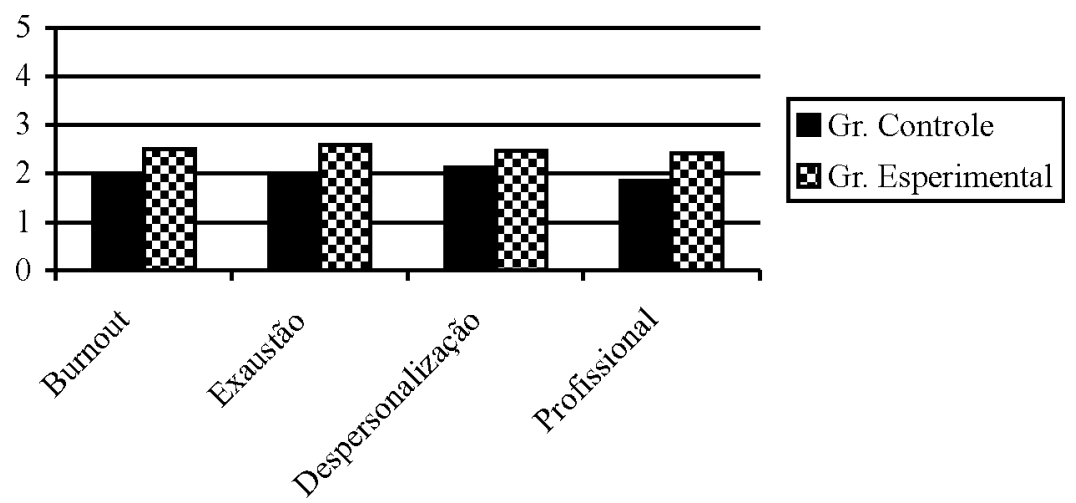

Figura I - Escores Médios dos Grupos de Controle e Experimental antes da intervenção 
Tabela I - Estatísticas das diferenças entre as médias dos resultados de Burnout antes da intervenção por meio de $t$ de Student

\begin{tabular}{lcccccc}
\hline \multicolumn{1}{c}{ Grupo } & $\mathrm{N}$ & Média & Desvio Padrão & $t$ & $\mathrm{gl}$ & $p$ \\
\hline Controle & 12 & 2,0045 & 0,41765 & 0,532 & 22 & 0,600 \\
Experimental & 12 & 1,9284 & 0,26556 & 532 & & \\
\hline
\end{tabular}

$t, p<0,05$ e gl (graus de liberdade) -índices estatísticos

experimental se apresentavam homogêneos, sem diferenças quanto ao seu nível de Burnout, isto é, as amostras poderiam ser consideradas de uma mesma população (Bisquerra, Sarriera \& Martinez, 2004).

Após o tratamento estatístico entre as médias dos dois grupos relacionados, antes e depois da intervenção, observou-se que, através da exposição do grupo experimental a VI intervenção, houve diferença significativa entre os grupos em sentido inverso do esperado (Tabela 2), isto é, esperava-se que o grupo, trabalhado com a técnica do grupo operativo, tivesse diminuído seu nível de Burnout e o grupo de controle mantivesse seu mesmo nível da fase pré-teste (Figura 2).

Observa-se que a Exaustão Emocional do grupo experimental apresentou diferença significativa em relação ao grupo de controle, demonstrando que os professores sentiram-se mais desgastados física e

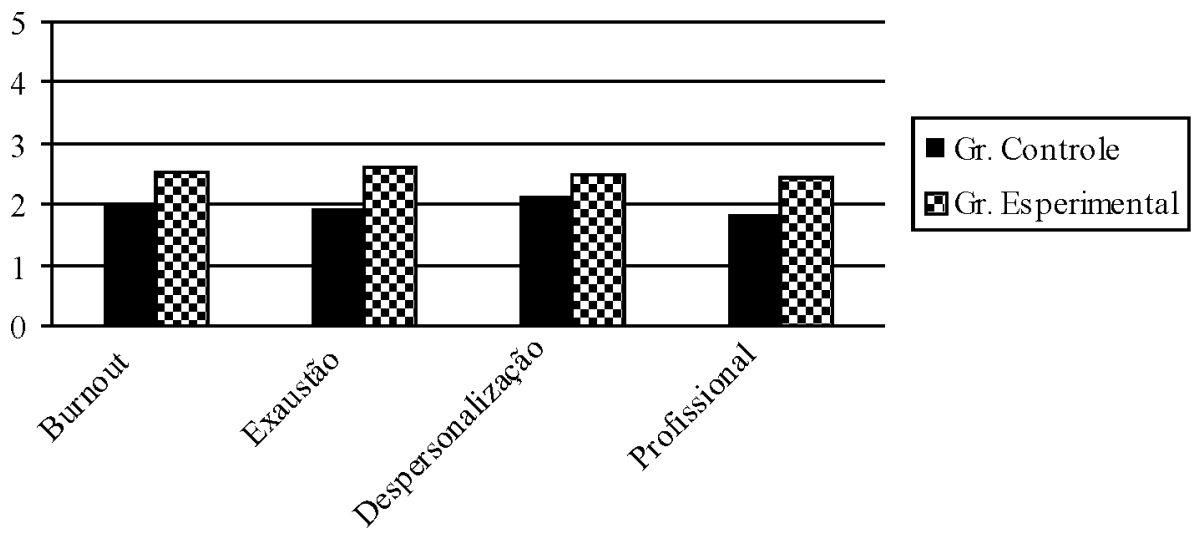

Figura 2 - Escores médios dos grupos controle e experimental após a intervenção

Tabela 2 - Estatísticas das diferenças entre as médias dos resultados por dimensão de Burnout para grupo controle e experimental depois da intervenção

\begin{tabular}{lllrrrrr}
\hline \multicolumn{1}{c}{$\begin{array}{c}\text { Dimensões do } \\
\text { Burnout }\end{array}$} & \multicolumn{1}{c}{ Grupo } & $\mathrm{N}$ & Média & $\begin{array}{c}\text { Desvio } \\
\text { Padrão }\end{array}$ & $t$ & $\mathrm{gl}$ & $p$ \\
\hline Exaustão & Controle & 2 & 2,18 & 6,00 & 2,219 & 22 & 0,03 \\
& Experimental & 2 & 2,82 & 8,14 & & & \\
\hline Realização & Controle & 2 & 2,01 & 0,55 & 1,901 & 22 & 0,07 \\
Profissional & Experimental & 2 & 2,43 & 0,52 & & & \\
& Controle & 2 & 1,47 & 0,55 & 2,234 & 22 & 0,03 \\
Despersonalização & Experimental & 2 & 2,05 & 0,72 & & & \\
\hline Burnout & Controle & 2 & 1,88 & 0,51 & $-2,734$ & 22 & 0,01 \\
& Experimental & 2 & 2,43 & 0,47 & 2,734 & & \\
\hline
\end{tabular}

t, $p<0,05$ e gl (graus de liberdade) -índices estatísticos 


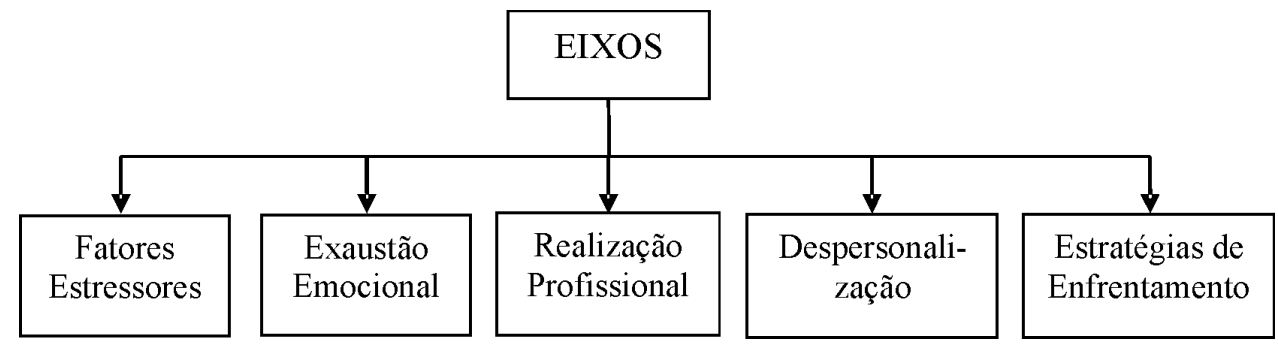

Figura 3 - Eixos categoriais apresentados nas sessões da intervenção

psiquicamente após a intervenção. A dimensão de despersonalização (Tabela 2) apresentou diferença significativa também entre os grupos após a intervenção, sendo que o grupo experimental apresentou maior nível de despersonalização. Em termos de Burnout geral o grupo experimental apresentou diferença significativa para maior nível desta síndrome do que o grupo de controle.

Este resultado, inesperado para os pesquisadores, levou à procura de maiores subsídios de compreensão, a partir do que tinha acontecido no decorrer da intervenção, assim como analisar o procedimento metodológico adotado, sempre relativo a um trabalho com docentes de escola particular desenvolvido no próprio contexto da escola.

\section{Análise de Conteúdo}

A partir da transcrição literal das gravações dos grupos operativos realizou-se a análise de conteúdo, segundo Bardin (1977). Esse processo apresenta e descreve as principais categorias e subcategorias que foram verificadas nos grupos operativos. O objetivo desta análise é de levantar as categorias nas suas significações, no conjunto do que foi debatido durante os grupos operativos, tanto nas suas convergências quanto nas suas divergências. Ressalta-se que as categorias e subcategorias foram agrupadas, a partir da análise de conteúdo, em cinco eixos temáticos principais: fatores estressores, exaustão emocional, realização profissional, despersonalização e estratégias de enfrentamento.

\section{Fatores estressores}

Esse eixo temático refere-se aos aspectos mais referidos como perturbadores do bom desempenho profissional e que exigem do professor uma quantidade considerável de sua energia, sendo eles: desamparo institucional, demonstrando a sensação de falta de respaldo institucional e a burocracia escolar, relativa ao preenchimento de formulários e fichas.

"Qualquer um chega, entra na sala e resolve o problema e acontece o seguinte, nós professores, parece que nós estamos desamparados. Nós olhamos um pro outro: o que que aconteceu? Nós vamos morrer abraçados. Essa situação. Só que chega num ponto, quem é que vai te ajudar?" S.6.

\section{Exaustão Emocional}

Esse eixo temático refere-se ao sentimento de esgotamento físico e mental dos professores, ao sentimento de falta de energia e de recursos emocionais próprios, considerado como o aspecto individual da síndrome de Burnout. Observa-se que os professores percebem e sentem sua profissão como sugadora de suas energias. As sensações de esgotamento são apresentadas através das subcategorias: o cansaço; o estresse; a necessidade de férias.

"Eu estou um pouco cansado. Eu acho que eles sugam, as crianças, eles sugam a gente. Chega uma hora que tem que dar uma parada, prá... prá te alimentar um pouco de novo."S.8.

\section{Realização Profissional}

Essa temática reflete como os professores percebem a valorização de sua profissão e como esta satisfaz suas necessidades de realização profissional. Os principais aspectos foram agrupados nas categorias: desvalorização e conquistas profissionais.

"essa questão de gostar do que faz é importante, mas outro ponto é a valorização social do nosso trabalho e que isso tem uma relação direta com a auto-estima. 
Os professores sofrem com o estigma de baixíssima autoestima”. S.I.

\section{Despersonalização}

Esse eixo temático refere-se à ocorrência de sentimentos e atitudes negativas para com os alunos e alunas, dirigindo-se a eles com frieza, ironia e cinismo. Este é o fator interpessoal da Síndrome de Burnout. As principais categorias são: características negativas dos alunos, imposição disciplinar e relacionamento negativo com alunos.

"Eu disse para eles: eu tenho que estar com o chicote aqui na mão. Eu vim cheia de boas intenções e não consegui fazer nada do que eu queria." S.2.

\section{Estratégias de Enfrentamento}

Esse eixo temático refere-se aos fatores que auxiliam e reforçam os professores no sentido de enfrentarem as dificuldades de sua profissão. Trata-se do eixo com maior diversidade de aspectos citados no transcorrer dos grupos operativos, e as principais categorias são: apoio social, atitudes com os alunos e características pessoais.

\section{Categoria I - Apoio Social}

A categoria apoio social foi referida em todos os encontros como a mais importante estratégia contra o estresse profissional. Ela consiste de atitudes ao fornecer e receber suporte social e pessoal e buscar uma maior união entre os professores. As principais sub-categorias citadas pelos professores foram: solidariedade e feedback dos colegas. Pode se observar que outras subcategorias, menos referidas, reforçam o valor deste aspecto para o enfrentamento de Burnout tais como: retroalimentação emocional, convívio com os colegas, amizade e cooperação grupal.

"Isso é uma situação muito chata porque a gente tem que se dar as mãos, e a gente está perdendo isso aí. Está muito individualizado. Ser mais solidário. A gente não está ajudando o outro, né?" S.7.

Categoria 2 - Atitudes em relação aos Alunos

Essa categoria descreve as principais atitudes positivas que os professores têm para com os alunos. Estas atitudes são apresentadas através de estratégias de ensino e do bom relacionamento com os alunos.
"Nós temos que seduzir nossos alunos, inovando com novidades, captando, comprando livros." S. 12

Categoria 3 - Características Pessoais do Professor

Essa categoria engloba as características pessoais dos docentes entendidas como importantes para o enfrentamento das dificuldades cotidianas da profissão, e as principais são: autenticidade e ser companheiro dos colegas.

“... eu acho que às vezes numa reunião, em escola particular isso acontece mais que em escola pública, tem uma certa coisa de ser muito bom o tempo todo que me incomoda e que eu pensei: será que nós vamos continuar fingindo? A gente vai fingir aqui também? Mas não, isso foi muito bom. Eu vejo especialmente por isso, eu me senti à vontade, eu não precisei fingir" S.9.

\section{Discussão}

Com os dados da análise de conteúdo, pode-se compreender que, no estágio atual de desenvolvimento da intervenção, a ansiedade dos professores tinha aumentado pelo fato de ampliar sua consciência e dividir com os colegas situações de conflito com a instituição. Porém, ao mesmo tempo em que aumentou o Burnout, formas ou estratégias de enfrentamento do estresse foram também apreendidas.

Nos dois primeiros encontros do grupo experimental, a percepção da vida de professor era de idealização profissional estereotipada e alienante demonstrando ser esta também a visão do grupo de controle, já que ambos são, neste momento, considerados estatisticamente como participantes da mesma amostra. A percepção idealizada conjuntamente com a falta de integração grupal dificulta a conscientização da realidade docente, tanto para os fatores estressores quanto aos aspectos gratificantes que a mesma proporciona. A partir do terceiro encontro, o grupo experimental entrou na fase de tarefa e conseguiu romper o estereótipo da idealização, permitindo-se uma intensa catarse dos sentimentos reprimidos, os quais foram analisados através das categorias de desgaste emocional, 
características negativas com os alunos e relacionamento negativo com os pais. Oscilando entre momentos de ansiedade suscitada pelo que era exposto e de momentos de apoio grupal, os professores construíram um forte sentimento de pertença e melhoraram sua comunicação. Os docentes puderam exercer, nos grupos operativos, o suporte social que tanto sentem falta dentro da instituição confirmando que a rede de apoio exercida entre colegas como um sentimento de união e respeito, facilita a vida laboral (Gil-Monte \& Peiró, 1997; Benevides-Pereira, 2002).

Através dos feedbacks entre os participantes e da maior autenticidade nas verbalizações, o grupo construiu um ECRO (esquema conceitual, referencial e operativo) próprio sentindo-se privilegiadamente diferenciado dos colegas que não participavam do processo operativo. Assim, ao serem compreendidos pelo grupo, os docentes permitiram-se analisar com maior acuidade sua profissão, aumentando sua conscientização e sensibilização com o contexto laboral. A cooperação entre os professores, no sentido da resolução de problemas comuns e do fortalecimento de apoio mútuo é considerada por Jesus (200I) e Codo, (2000) como uma das principais formas de lidar com o mal-estar profissional. A oportunidade de debater em grupo as experiências vividas na docência possibilitou aos professores tanto uma leitura crítica como uma apropriação grupal ativa desta realidade. O grupo passou de uma visão idealizada alienante de sua profissão para uma atitude investigadora, na qual cada resposta obtida transforma-se em uma nova pergunta. Este grupo atingiu o objetivo da aprendizagem pichoneana, que é sinônimo de mudança (Abduch, 1999).

O aumento estatístico no nível de Burnout, observado na segunda medição do $\mathrm{MBI}$, traduz quantitativamente esta situação e assim se pode integrar as análises de estatística inferencial, de conteúdo e de processo grupal. Enquanto o grupo experimental, através da técnica operativa, construiu uma adaptação ativa à realidade escolar, - grupo de controle manteve a mesma percepção idealizada estereotipada do começo do ano, sendo que esta equivalência pode ser observada nos dois resultados quantitativos apresentados por este grupo. Os dados quantitativos demonstram claramente que o grupo experimental, ao ser mobilizado pela técnica de grupo operativo, aumenta seu nível de Burnout, dentro do estágio mobilizado no qual se encontrava. Esteves (1994) esclarece que a comparação entre a real prática pedagógica e os ideais almejados no trabalho docente, aumenta o nível de ansiedade do professor. Embora a técnica operativa tenha elevado o nível de Burnout no grupo experimental, criou, ao mesmo tempo, uma maior consciência de estratégias de enfrentamento para o esgotamento profissional. No entanto, seria necessário seguir o processo com maior número de sessões, para constatar com maior fidedignidade, se esta técnica proporcionaria condições de desenvolver e consolidar melhor as estratégias de enfrentamento e proporcionar maior controle sobre o nível de ansiedade.

A proposta de concretizar e sistematizar a realização de grupos operativos com professores, dentro das escolas, inclui a consciência crítica, por parte da direção e dos setores especializados, da necessidade de valorização do docente como pessoa e como profissional. Além disso, ao se entender que a Educação é um processo eminentemente relacional, os possíveis benefícios produzidos pelos grupos operativos contemplam não apenas os professores, mas transcendem os limites do grupo alcançando os alunos e toda a comunidade escolar.

\section{Referências}

Abduch, C. (1999). Grupos operativos com adolescentes. Cadernos Juventude, Saúde e Desenvolvimento,28, 289 299.

Abreu, K. L., Stoll, I., Ramos, L. S., Baumgardt, R. A., \& Kristense, C. H. (2002). Estresse ocupacional e Síndrome de Burnout no exercício profissional da Psicologia. Psicologia: Ciência e Profissão, 22, 23-30.

Bardin, L. (1977). Análise de Conteúdo. Lisboa: Persona.

Benevides-Pereira, A. M. B. (2002). O Processo de adoecer no trabalho. Em A. M. B. Pereira (Org.), Burnout: Quando 
o trabalho ameaça o bem-estar do trabalhador (pp. 2I-9I). São Paulo,SP: Casa do Psicólogo.

Bisquerra, A. R., Sarriera, J. C., \& Martinez, F. (2004). Introdução à Estatística: enfoque informático como pacote estadístico SPSS. Porto Alegre, RS: Artmed.

Bleger, J. (1985). Temas de Psicologia. São Paulo,SP: Martins Fontes.

Carlotto, M. S. (2002). Síndrome de Burnout e a Satisfação no Trabalho: um estudo com professores universitários. Em A. M. Pereira (Org.), Burnout: quando o trabalho ameaça o bem-estar do trabalhador (pp.l87 - 2II). São Paulo,SP: Casa do Psicólogo.

Codo, W. (2000). Educação: carinho e trabalho. Burnout, a síndrome da desistência do educador, que pode levar à falência da educação. Petrópolis,RJ: Vozes.

Codo, W., \& Vasques-Menezes, I. (2000). O que é burnout. Em W. Codo (Org.). Educação: carinho e trabalho. Burnout, a síndrome da desistência do educador, que pode levar à falência da educação (pp.237 - 253 ). Petrópolis,RJ: Vozes.

Esteves, J. M. (1994). El malestar docente. Barcelona: Ediciones Paidós Ibérica.

Gil-Monte, P., \& Peiró, J. M. (1997). Desgaste psíquico em el prabajo: el Síndrome de Quemarse. Madrid: Editorial Síntesis.

Jesus, S. N. (1998). Bem-estar dos professores. Estratégias para realização e desenvolvimento profissional. Porto: Porto Editora.
Jesus, S. N. (200I). Perspectivas para o bem-estar docente: uma lição de síntese. Cadernos do Centro de Recursos de Informação e Apoio Pedagógico(v. 29). Lisboa: Edições ASA.

Lobo, M. C. (1999). Maria Sem-Vergonha de ser professora. Porto Alegre,RS: Artes Médicas.

Maslach, C., \& Jackson, M. (198I). Maslach Burnout Inventory Manual (MBI). Palo Alto, CA: Consulting Psychologist Press.

Maslach, C., \& Leiter, M. P. (1999). Trabalho: fonte de prazer ou desgaste? Guia para vencer o estresse na empresa. Campinas,SP: Papirus.

Moura, E. P. (1997). Saúde Mental e trabalho: esgotamento profissional em professores da rede de ensino particular de Pelotas/RS. Dissertação de Mestrado em Psicologia Social, Faculdade de Psicologia, Pontifícia Universidade Católica do Rio Grande do Sul, Porto Alegre.

Osório, L. C. (2000). Grupos, teorias e práticas. Acessando a era da grupalidade. Porto Alegre,RS: ArtMed.

Pichon-Riviére, E. (1977). O Processo Grupal. São Paulo,SP: Martins Fontes.

Witter, G. P. (2003). Professor e estresse: análise de produção científica. Psicologia Escolar e Educacional, 7, 33-46.

Recebido em: 04/05/2005

Revisado em: 14/02/2006

Aprovado em: 10/03/2006

Sobre os autores:

Vivien Rose Böck (boclbend@terra.com.br ) é mestre em Psicologia pela Pontifícia Universidade Católica do Rio Grande do Sul.

Jorge Castellá Sarriera (sarriera@terra.com.br) é doutor em Psicologia, professor convidado da Universidade Federal do Rio Grande do Sul e professor colaborador no pós-graduação em Saúde Coletiva da Universidade do Rio do Sinos.

Endereço para correspondência

Jorge Castellá Sarriera

Universidade do Vale dos Sinos

Av.Unisinos, 950

93022000 - São Leopoldo, RS - Brasil 